\section{Los efectos tempranos del financiamiento para la Educación Superior}

Por Eugenio Giolito *
Al revisar datos de rendimiento sobre Este articulo se refiere al impacto que la población de estudiantes de Chile para pudo tener la reforma, no sobre los estuel periodo 2002-2012, encontramos que diantes que efectivamente obtuvieron la implantación del Crédito con Aval del credito, sino sobre el comportamiento de Estado, CAE produjo una reducción en estudiantes secundarios que repentinalas tasas de abandono de entre el $10 \mathrm{y}$ el mente se enteraron de la gran posibilidad 25\%, con un impacto concentrado en es- que tenian de acceder a la educación sutudiantes que comenzaron la educación media en colegios cuyo promedio PSU era inferior a los 475 puntos. Tambièn encontramos, utilizando datos de la Encuesta CASEN, impactos positivos sobre la detenUno de los temas mís dera cuál ha sido el verdadero impacto del CAE para estudios superiores. Si bien, dicha política, iniciada en el año 2006 fue vital en la expansión de la matrícula universitaria (básicamente en universidades fuera del Consejo de Rectores), tambièn deja en evidencia que el sistema universitario chileno no estaba preparado para un crecimiento de tal magnitud en tan poco tiempo. Varios estudios recientes (Rau, Rojas, \& Urzuar, 2013) señalan que los estudiantes que obtienen el credito son menos propensos a abandonar la universidad. Sin rios no obtienen mejores ingresos en el mercado laboral, probablemente debido los incentivos perversos introducidos por la reforma, y que han afectado negativamente la calidad de la educación superior. torno a la educación superior en Chite es dio estos ya tenian acceso a crédito mediante la admisión a universidades del CRUCH. El gráfico 1 muestra la fracción de estudiantes de cuarto medio que rindieron la PSU en 2005 (antes del CAE), 2009 y 2013. Nótese que prácticamente todos pus estudiantes de colegios con promedio PSU de más de 550 puntos ya daban la prueba previamente a la reforma, en tanto que los de colegios de menor puntaje exhiben apreciables au2013) por lo que es de entre 2005 y 2009 (no asi entre 2009 de mayor puntaje no hen sido afecta los por la reforma ly por to tanto constituyen nuestro grupo de "control").

Por lo tanto, si queremos analizar el impacto de la imple-

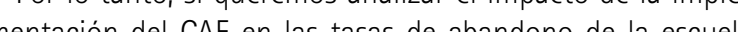
me lio 20\%) lo que hacemos es comparar el cambio en las tasas de abandono antes $y$ después de la reforma para el grupo de estudiantes "tratados" (aquellos que comenzaron la enseñanza media antes de 2006 en colegios de menos de 550 puntos) con aquellos en el grupo de "control" Es aqui cuando comprobamos que la implantación del CAE produjo una reducción en las tasas de abandono de entre 10 y 25\%, estando concentrado este impacto en estudiantes que comenzaron la educación media en collegios cuyo promedio PSU era inferior a los 475 puntos.

Mientras que lo anterior nos habla de un fuerte cambio de comportamiento en estudiantes para los cuales la creación del CAE implico generarles una expectativa de acceso a la educación superior, cremos que la caida en el abandono no disponibles no nos permiten saber si en efecto a losedieron). Para averigur otros márgenes en que et CAE puede haber influido, tomamos una muestra de la Encuesta CASEN hare perído 1994-2011 y repetimos el ejercicio anterior. Dado que los resultados son consistentes con los de la base de rendimiento, nos preguntamos si la reforma puede haber tenido un mpacto sobre el embarazo adolescente. En este caso, en vez de la PSU promedio del colegio, calculamos el promedio de los colegios de la comuna de residencia del individuo en 2005. Como puede verse en la gráfico 2, a partir de 2006 se observa un aumento en la finalización escolar de hombres y mujeres (edad 18-21) y una caida en el abandono de mujeres de 15 17 anos. La respuesta al impacto sobre embarazo adolescente puede verse en la figura 3, para tres especificaciones distin-

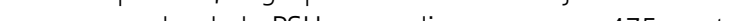

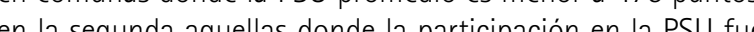
menor at $00 \%$ en 1975 y tercer (a nivelindividull mujes en los 2 primeros quintiles. Nótese que en ambos casos las caida comienza en 2006 y no responden a tendencias previas En cada caso se controla por los inobservables fijos a nivel comuna y por la disponibilidad de la "pildora del dia después gratuita" a partir de 2009

Creemos que el tema merece seguir siendo investigado. Esto es sólo un ejemplo de las muchas dimensiones que se tocan cuando se habla de reforma educativa.

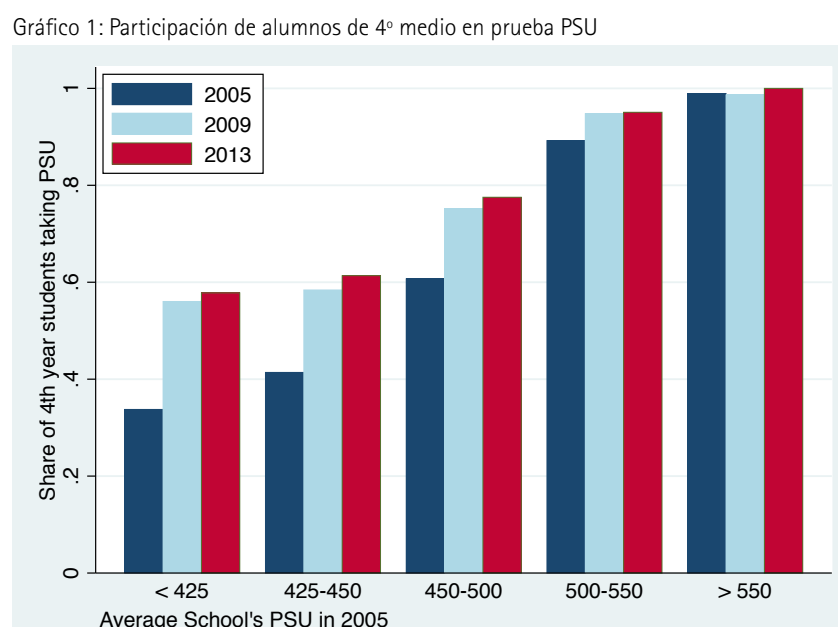

Gráfico 2: Abandono escolar y finalización de escuela media. CASEN 1994-2011
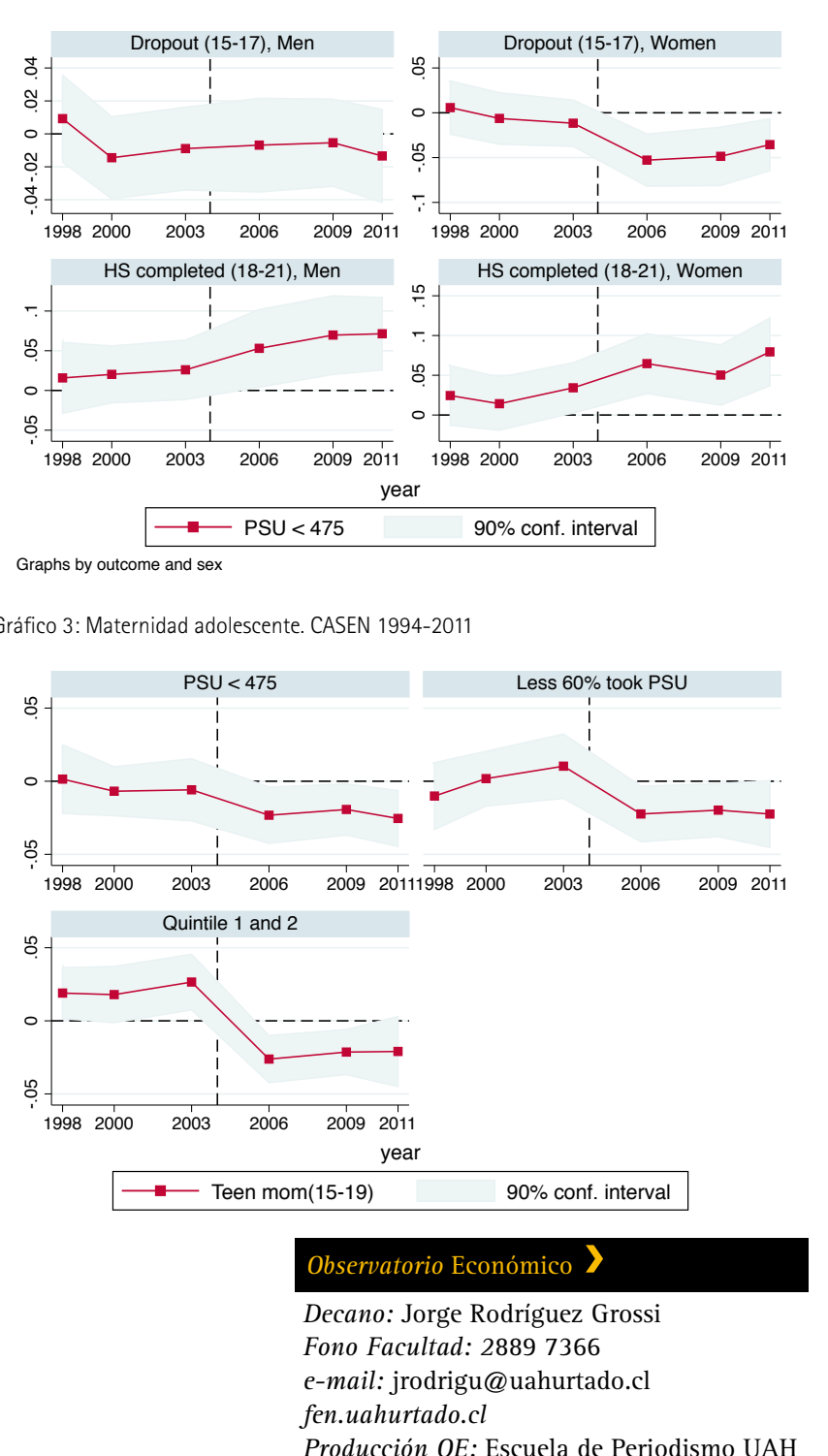